\title{
Measurement of Nitric Oxide and Reactive Oxygen Species in the Vascular Wall
}

\author{
Rosalia Rodriguez-Rodriguez ${ }^{1, *}$ and Ulf Simonsen ${ }^{2}$ \\ ${ }^{I}$ Department of Pharmacology, School of Pharmacy, University of Seville, Seville, Spain \\ ${ }^{2}$ Department of Biomedicine - Pharmacology, Aarhus University, Aarhus, Denmark
}

\begin{abstract}
Vascular generation of nitric oxide (NO) plays an important role in the regulation of blood flow, and is counterbalanced by the formation of radical oxygen species (ROS). Thus, an imbalance in vascular NO and ROS production contributes to endothelial dysfunction, which is associated with cardiovascular disease. Here we review the main and commonly used methods that have been applied to determine vascular NO and ROS. Only NO microsensors, electron spin resonance (ESR), and NO sensitive fluorescent probes allow real time measurement of NO levels in cell suspensions, cell cultures, and isolated vascular segments in vitro, and of these techniques only NO microsensors have so far been developed for real time detection of $\mathrm{NO}$ in vivo. ROS formation has been detected in cell cultures by lucigeninenhanced fluorescence, fluorescent probes e.g. 2',7'-dichlorodihydrofluorescein and dihydroethidium, by use of ESR, and also by electrochemical detection. The limitations of the electrochemical microsensors include interference from other substances, physical force on the sensors, and influence of temperature and changes in $\mathrm{pH}$ that may lead to artifactual changes in current. Therefore, specificity testing and calibration are pivotal, and in case of ROS, application of more than one technique is recommendable. Technical advances have allowed simultaneous detection of both NO and superoxide anion by use of electrochemical microsensors. Miniaturizing the sensors may also allow incorporation of those in lab-ona-chip and may lead to real time measurements of NO and ROS in the coronary circulation in situ, and hence provide direct evaluation of endothelial and vascular function in cardiovascular disease.
\end{abstract}

Keywords: Endothelium, Microelectrode, Nitric Oxide, Reactive Oxygen Species, Superoxide Anion, Vascular.

\section{INTRODUCTION}

Reactive oxygen (ROS) and reactive nitrogen (RNS) species are involved in a wide range of biological functions, from physiological events such as neurotransmission to pathological situations such as inflammation, cancer, neurodegeneration and cardiovascular diseases. Particularly, both kinds of substances play a critical role in the maintenance of vascular homeostasis and injury $[1,2]$.

The prototype of RNS is nitric oxide (NO), which was identified decades ago as the long sought "endothelialderived relaxing factor". NO was reported to be synthesized by endothelial cells in blood vessels and rapidly diffused to the adjacent smooth muscle cells inducing vasodilatation. The discovery of the role of NO on vascular tone, which resulted in the Nobel Prize in Physiology and Medicine in 1998 to R.F. Furghgott, L.J. Ignarro and F. Murad, initiated an intensive research trying to elucidate how NO acts not only in vascular tissue, but also in the brain and immune responses. It has been also demonstrated that NO, in addition to relaxing blood vessels, inhibits platelet adhesion and aggregation as well as vascular smooth muscle cell

*Address correspondence to this author at the Rosalia RodriguezRodriguez, Department of Pharmacology, School of Pharmacy, University of Seville, Postal address: C/ Profesor Garcia-Gonzalez 2. 41012 Seville, Spain; Tel: +34954557443; Fax: +34954556074; E-mail: rodriguezr@us.es proliferation, and decreases the synthesis of proinflammatory factors that promote vessel injury (Fig. (1)). The initial event generating the development of a vascular disease is a dysfunction in the endothelial layer of the blood vessel, changing the vasoreactivity and increasing permeability to pro-inflammatory mediators. Such endothelial dysfunction may arise from different causes including arterial hypertension, dyslipidemia, and diabetes and is associated with oxidative stress $[1,2]$. The dysfunctional endothelium leads to a reduced formation of vasoprotective and vasodilating mediators such as $\mathrm{NO}$, and in turn promote the formation of vasoconstricting mediators (e.g. $\mathrm{TXA}_{2}$, superoxide anion) inducing vascular inflammation and smooth muscle cell migration. Therefore, substances and drugs able to promote endothelial NO release and/or to reduce the presence of deleterious mediators such as superoxide anion $\left(\mathrm{O}_{2}^{-}\right)$are potential candidates to provide cardiovascular protection by restoring endothelial function [3].

The decreased bioactivity of vascular NO due to endothelial dysfunction may be, on one hand, associated to a lower synthesis of the mediator by the endothelial NO synthase (eNOS) or related to a higher breakdown of $\mathrm{NO}$, especially by an increased oxidative stress. An important mechanism reducing vascular NO bioavailability is a rapid oxidative inactivation by reaction with $\mathrm{O}_{2}{ }^{-}$. In addition to enzymes directly regulating ROS formation e.g. NADPH oxidase and degradation e.g. superoxide dismutases (SOD), 


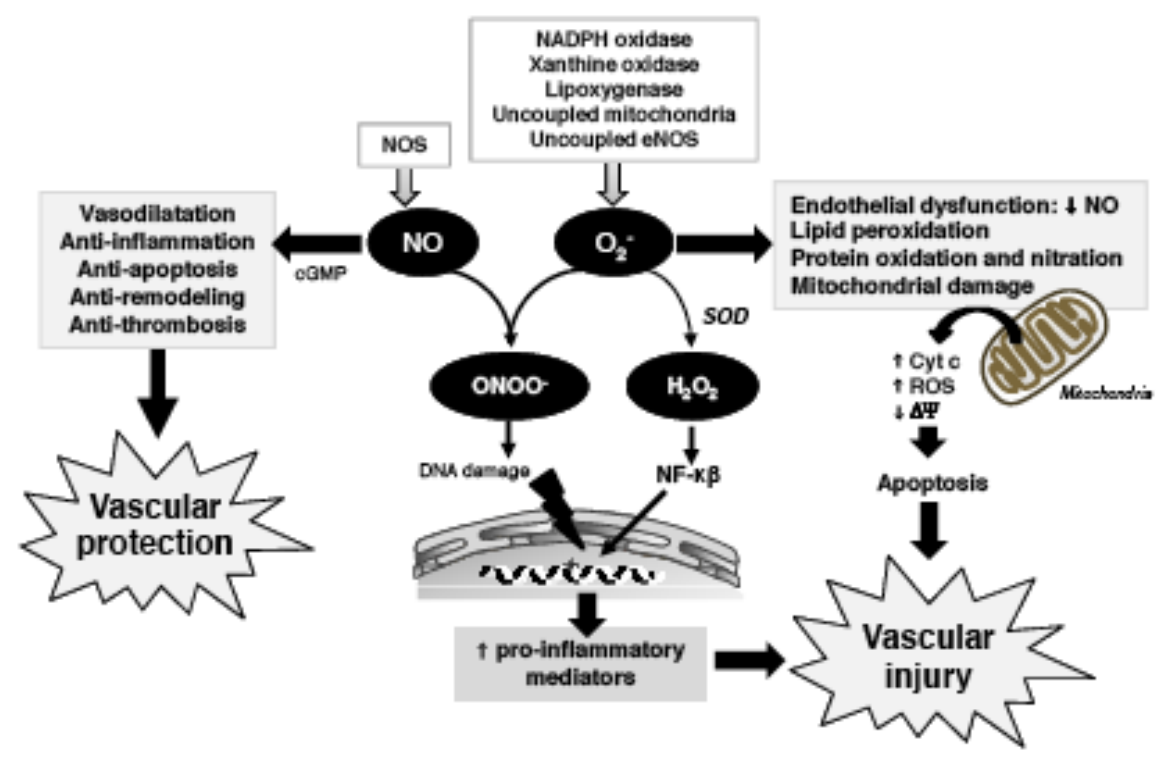

Fig. (1). Role of NO and ROS in regulating vascular functions. Physiological levels of vascular NO provide protection to blood vessels against damages. Conversely, increased levels of $\mathrm{O}_{2}^{-}$inactivate $\mathrm{NO}$, and counteract its vasoprotective effects. ROS produced from several sources mediates many of the responses to vascular injury by impairing vessel tone and by inducing an inflammatory state and apoptosis. Cyt c: cytochrome c; NOS: nitric oxide synthase; SOD: superoxide dismutase.

eNOS may also be a source of oxidative stress underlying endothelial dysfunction (Fig. (1)). Accordingly, when the eNOS substrate L-arginine or an essential cofactor of eNOS, tetrahydrobiopterin $\left(\mathrm{BH}_{4}\right)$ is oxidized to dihydrobiopterin $\left(\mathrm{BH}_{2}\right)$ thus increasing the $\mathrm{BH}_{2} / \mathrm{BH}_{4}$ ratio, eNOS becomes uncoupled from L-arginine and shifts its product profile to $\mathrm{O}_{2}^{-}$, instead of $\mathrm{NO}$, by using molecular oxygen [4].Consistent determinations of vascular NO and ROS levels and their generation is relevant to understand the mechanisms underlying vessel damage as well as to identify potential targets for therapeutic interventions. Particularly, there is increasing evidence that several natural products and plant extracts from foods, drinks and herbal medicines may influence vascular production of $\mathrm{NO}$ and ROS thereby providing protection against cardiovascular diseases [2, 3]. The identification of such compounds and characterization of their cellular actions, extensively associated to antioxidant properties, may increase the understanding of the regulation of ROS and RNS and could provide valuable strategies for the prevention or treatment of cardiovascular diseases.

Numerous methods for detecting NO and ROS such as $\mathrm{O}_{2}^{-}$and $\mathrm{H}_{2} \mathrm{O}_{2}$ have been developed in order to measure (direct or indirectly) these molecules by electrochemical, chemiluminiscent and spectrophotometric techniques $[5,6]$. Nevertheless, the very rapid time course of events in endothelial dysfunction makes monitoring changes in these molecules electrochemically in real time the most useful and reliable approach. Additionally, the short half-life (seconds) of reactive oxygen and nitrogen species and the efficient systems scavenging them require that any detection method must be sensitive enough and must allow in situ measurements in the tissues of interest. Therefore, technology allowing both real-time and direct measurements of $\mathrm{NO}, \mathrm{O}_{2}^{-}$or other free radicals in vascular cells or tissues is the aim of an intensive research nowadays. Developing these methods will permit in situ measurement of pharmacologic substances or antioxidants aimed to prevent endothelial dysfunction and the subsequent vessel injury. The present review is focused in commonly used approaches to detect oxygen and nitrogen reactive species, with special attention paid to $\mathrm{NO}$ and $\mathrm{O}_{2}{ }^{-}$detection in vascular cells and tissues and how these approaches are used to evaluate the effects of pharmacological substances and/or antioxidants on vascular function.

\section{VASCULAR NO DETECTION}

NO levels are altered and of importance for the development of several diseases e.g. low NO levels is related to Parkinson's disease, cardiovascular pathologies and conversely, high NO levels may participate in inflammatory diseases and cancer. Therefore, from a medical and biochemical point of view, it is important to detect the NO flux in living cells under normal or pathological circumstances, and if possible, a direct and real-time determination in response to different stimuli or drugs. Numerous studies have indirectly estimated NO levels in biological samples by measurements of NOS activity, NO metabolites nitrate and nitrite using Griess reaction or, in many cases, by using pharmacological tools that inhibit the formation of NO [5]. Although these approaches are easily applied and provide indications about the involvement of NO pathway in the physiological event under evaluation, cross reactivity with related substances and the real production of NO involved is underestimated. Only direct and real time measurements of NO levels in cells and tissues allow a conclusion on the exact NO concentration produced by a particular cell in response to a stimulus or in basal conditions. However, so far the results obtained by different investigations regarding to direct measurements of $\mathrm{NO}$ in living cells are disappointing since there is a huge variability in tissue NO concentrations determined by different groups using different direct electrochemical detectors $[7,8]$. 

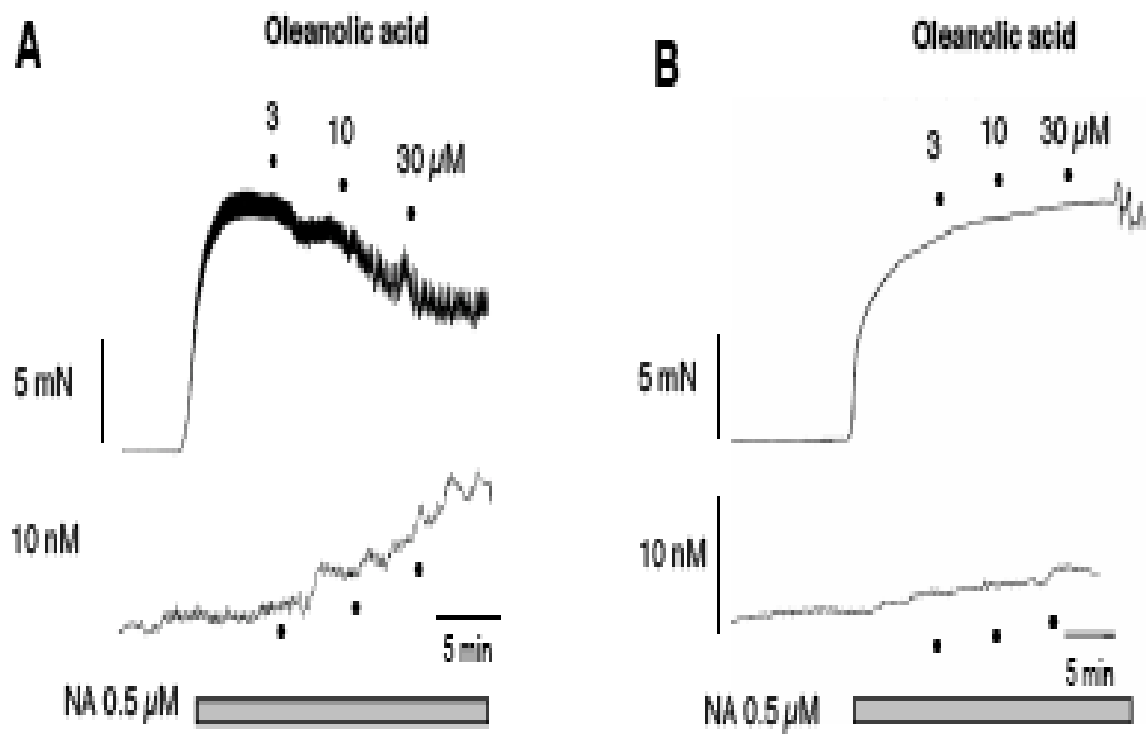

Fig. (2). Simultaneous determination of NO (lower original traces) and dilatation (upper original traces) induced by the natural triterpenoid oleanolic acid in rat superior mesenteric arteries by using a selective NO-microelectrode and wire myography. Oleanolic acid induced simultaneous arterial vasorelaxation and NO release (A). These responses were abolished in endothelium-denuded arteries (B). Adapted from [22].

\subsection{Electrochemical NO Microsensors}

NO microsensors allow direct and real-time detection of NO generated in the nanomolar range both in vitro and in vivo [7-10]. The principle is that $\mathrm{NO}$ is oxidized at the surface of a working electrode, thus transferring one electron from the NO molecule to the anode generating current and nitrosonium cation $\left(\mathrm{NO}^{+}\right)$, which is finally converted to nitrite $\left(\mathrm{NO}_{2}{ }^{-}\right)$. The first successful $\mathrm{NO}$ sensor was a miniature solid-state probe, based on the Clark electrode for the detection of oxygen, with a diameter of approximately 2 $\mathrm{mm}$ [7]. Malinski and co-workers [11] developed a much smaller microsensor based on a carbon fibre with a dual coating compromising polymerized metalloporphyrin and an outer layer of Nafion, which excluding access of nitrite. Most of published studies with NO sensors are based on the described electrode type (see ref. [7]).

The electrode is commonly operated by applying an optimal poise potential for detection of $\mathrm{NO}$ relative to a reference electrode and hence detecting current by direct amperometry. By sweeping the electrode through a range of potentials it is also possible to construct a voltammogram which based on the optimal poise voltage for a substance provides information about the substance that is being oxidized at the working electrode. Commercially available needle-type NO-sensors provide tip diameters ranging from $0.1 \mu \mathrm{m}$ to $2 \mathrm{~mm}$. Manufacturers establish that the arrangement of the electrodes, in combination with highly selective gas permeable membranes and special multilayered selective coatings result in NO-sensors with excellent performances and minimal susceptibility to environmental noise. No specific information is available concerning the nature of the membranes and their mechanisms of action, which is probably based on size and charge exclusion effects [12]. For further information about specific NO microsensors and how they are constructed please consult previous reviews $[7,11,12]$.
NO microsensors have been applied for measurements in cell suspensions e.g. measurements of NO formation by platelets and leukocytes [13], measurements of NO formation in cell cultures (e.g. [14-17]), and in isolated arterial segments (e.g. [18-22]) (see ref. [7]). NO microsensors allow simultaneous measurements of $\mathrm{NO}$ concentration and vascular tone in isolated arteries [20-23]. An example of simultaneous measurements is shown in Fig. (2), where the experiment revealed that the natural triterpenic acid, oleanolic acid, induces endotheliumdependent relaxations mediated by low nanomolar $\mathrm{NO}$ concentrations in arterial segments [22]. In addition to the NO levels altered by agonists or drugs, it is possible to estimate the basal concentration by an NO scavenger by observing the decrease in NO concentration [20, 24]. NO microsensors inserted through catheters have also been applied for in vivo experiments and yielded information of NO release in connection with flow-induced vasodilation [25], alterations in NO concentration during limb ischaemia [26], and NO concentration during hypoxia in the brain [27]. Moreover, development of catheters containing a microsensor detecting NO by back conversion of nitrite to NO has recently allowed the measurement and evaluation of NO concentration in the coronary circulation of patients with dilated cardiomyopathy [9].

The microsensors for electrochemical detection of $\mathrm{NO}$ have a series of limitations that increase with the complexity of the system where the NO flux is measured. The NO microsensors require daily calibration and extensive testing for specificity to avoid that non-NO substances (e.g. catecholamines, tyrosine, nitrite) interfere with the measurements. Moreover, the microsensors should be tested to address whether changes in $\mathrm{pH}$, oxygen, and vehicles may influence the measurements [7]. Physical force on the sensor will also change the measurements, but this appears to be solved with the development of protected nanosensors or in 
case of isolated vascular segments to measure simultaneously changes in force and NO levels. However, increasing protective layers on the sensors often increases the diffusion distance and hence response time, while minimizing the electrode surface area is often associated with decreases in the sensitivity of the NO microsensor.

\subsection{Electron Spin Resonance (ESR) with NO-specific Spin Traps}

ESR (or electron paramagnetic resonance - EPR - spin trapping) spectroscopy is one of the most commonly used method for detection of paramagnetic species. This implies the absorption of microwave energy by paramagnetic species in the presence of an external magnetic field resulting in the transition of spin states. NO is a relatively stable radical that can conjugate with specific compounds called "spin traps", fundamentally metal complexes that are able to selectively react with NO prolonging its half life and generating a characteristic spectrum that can be quantitatively analyzed by ESR [28]. Numerous investigations describe the use of ESR spin trapping methods to detect $\mathrm{NO}$ in several in vitro and in vivo systems including renal and vascular regions [29, 30] as well as in tumors [31]. Different iron compounds have been used to specifically trap NO such as diethyldithiocarbamate (DETC) and N-methylglucamine dithiocarbamate (MGD) [32]. MGD is useful for extracellular detection of NO whereas DETC is especially helpful for monitoring NO in the cellular lipid membrane [6].

Several studies have identified the use of colloid iron (II) DETC $\left(\mathrm{Fe}(\mathrm{DETC})_{2}\right)$ as the most promising spin trap for vascular NO detection by $\operatorname{ESR}[6,32,33]$. Monitoring of NO generated in blood vessels as well as in human umbilical endothelial cells has been successfully reported using colloidal $\mathrm{Fe}^{2+}$-DETC prepared by mixing DETC and $\mathrm{Fe}^{2+}$ in a concentrated Krebs-HEPES solution [34]. This spin trap is specific for bioactive $\mathrm{NO}$ and does not detect nitrite or nitrate. Besides, the $\mathrm{Fe}(\mathrm{DETC})_{2}-\mathrm{NO}$ complex allows measuring of cumulative quantity of bioactive NO generated over time. Although ESR offers the advantage of specific and direct monitoring of $\mathrm{NO}$ in situ, it has some limitations including the special handling required for $\mathrm{Fe}(\mathrm{DETC})_{2}$ colloid to prevent oxidation and the fact that $\mathrm{Fe}(\mathrm{DETC})_{2}-\mathrm{NO}$ complex can be easily oxidized by extracellular $\mathrm{H}_{2} \mathrm{O}_{2}$ and $\mathrm{O}_{2}^{-}$generating an ERS silent form [6]. In addition, ESR measurements often require low temperatures and long recording times thus hampering the use of this approach for $\mathrm{NO}$ and ROS detection in physiological conditions $[6,28]$.

\subsection{Fluorescent Indicators of NO}

Imaging of NO production in living cells has been achieved using a range of organic-based and metal-based fluorescent indicators that interact with $\mathrm{NO}$ in a fast, sensitive and selective manner. In both instances, the aim is to modify the fluorescent properties of the probe by an interaction with NO [35]. Organic probes use fluorophores with functional groups able to quench their fluorescence until being restored by a specific reaction with NO. Organicbased indicators incorporating fluorescein such as diaminofluoresceins (DAFs) were the first fluorescent NO sensors developed and up to now are commonly used for NO detection. The widespread application of DAFs for NO determination is related to their high selectivity to NO since they do not react with $\mathrm{NO}$ metabolites and other reactive species including $\mathrm{O}_{2}^{-}$and $\mathrm{H}_{2} \mathrm{O}_{2}$. DAFs are also extremely sensitive NO indicators showing a detection limit between 3$10 \mathrm{nM}[35,36]$. These probes are available as cell permeating acetoxymethyl esters (AM) or diacetates that undergo hydrolysis intracellularly to liberate the active compound. Currently, 4,5-diaminofluorescein (DAF-2) has been widely used for vascular detection of NO in cultured cells [37-41], isolated and intact vessels [42, 43] in combination to fluorescence microscopy or flow cytometry. The main limitations of the DAFs probes are fluctuations of the fluorescence by $\mathrm{pH}$ alterations in addition to a notorious autofluorescence background as a consequence of an intracellular accumulation of DAF [36, 44, 45]. Another limitation is that the simultaneous presence of a NO source and a superoxide source such as xanthine oxidase may decrease the fluorescence of DAF, resulting in underestimation of NO production. On the other hand, it has been reported that the presence of $\mathrm{H}_{2} \mathrm{O}_{2}$ may increase the rate of fluorescence of DAF thus generating false-positive readings under conditions of low rates of $\mathrm{NO}$ production [46]. Also, the autoxidation of DAF, which is potentiated by light exposure and interference with oxidants (e.g. superoxide), may lead to a fluorescence spectra indistinguishable from that of the NO adduct of DAF [46]. In addition, these fluorescent indicators of NO are oxygen sensitive and therefore are not recommended to use under hypoxic conditions [47].

These facts limit the sensitivity of this probe and may interfere with the detection of low concentrations of NO in living cells. In order to improve the $\mathrm{pH}$ tolerance and to reduce autofluorescence of these NO indicators, Kojima and co-workers [48] developed a membrane-permeable fluorescent indicator for NO based on the rhodamine chromophore, DAR-4M AM, which was successfully applied to practical bioimaging of $\mathrm{NO}$ produced in bovine aortic endothelial cells. In that study, the detection limit of NO was $7 \mathrm{nM}$, and the fluorescence showed no $\mathrm{pH}$ dependency above $\mathrm{pH} 4$. Nevertheless, later investigations questioned the specificity of DAR-4M AM, since it is a suitable fluorescent probe for qualitative assessment of RNS, but not specific for $\mathrm{NO}$, and the fluorescent yield is affected by the presence of other oxidants $[49,50]$. Subsequently, new probes based on the boron dipyrromethene (BODIPY) structure have been synthesized for ex vivo NO imaging. These BODIPY-based probes have been used to detect NO production in a cell line derived from rat pheochromocytome and in human vascular endothelial cells. Although authors described this probe as an useful approach for NO detection showing short reaction time, high photostability and minimal fluorescence background [51], no references have been reported about the specificity or any interference of the indicator with other reactive species different from NO in living cells.

The use of organic-based fluorescent dyes for NO detection are, in general, limited by several factors, since any change in the redox state of a cell may alter the degree of oxidation of the fluorophore leading to a modification in the amount of radical species able to react with NO and, hence, an alteration in the fluorescence. Therefore, an interpretation 
of the fluorescent signal in terms of NO is problematic and quantification of the signal attributed to NO is unfeasible.

As an alternative to organic-based probes, fluorophores complexed with $\mathrm{Cu}^{2+}$ have been recently designed for NO detection. Binding of $\mathrm{NO}$ causes reduction to $\mathrm{Cu}^{+}$leading to the production of $\mathrm{NO}^{+}$and the subsequent increase in fluorescence emission [52]. Although this Cu-based fluorescent probe has effectively detected NO production in vascular endothelial cells and macrophages, the lack of a consistent calibration of the response makes this approach still preliminary for NO quantification [8].

To overcome the limitations of the described fluorescent NO dyes, Sato and co-workers [53, 54] developed a genetically encoded fluorescent NO indicator, named CGY, that reversibly detects NO with a high sensitivity in living cells (detection limit of $0.1 \mathrm{nM}$ ). The basis of the sensor is the endogenous cell expression of soluble guanylate cyclase (sGC), which is a receptor protein for the selective recognition of NO leading the interaction to cGMP production. In this study [53], vascular endothelial cells were transfected with a plasmid vector encoding a fluorescent indicator for cGMP and fluorescence resonance energy transfer is recorded upon excitation of the cells. The sensitivity and reversibility of this genetically encoded NO indicator make it a powerful tool to measure nanomolar dynamics of NO concentrations in vascular cells and tissues. Despite of the interest of this approach, it involves a potentially problematic cross-talk with cGMP generated from endogenous GC in endothelial cells and does not estimate the bioavailable NO levels. Also, the sensitivity of the method may be modulated by the activity of the phosphodiesterases that catalyze the hydrolysis of cGMP to GMP.

\section{VASCULAR ROS DETECTION}

ROS are generated in vascular cells by oxidases such as NADPH oxidases, xanthine oxidase, lipoxygenases, cytochrome $\mathrm{P} 450$, or by uncoupling of the mitochondrial respiratory chain and uncoupled eNOS (Fig. (1)). Production of ROS is counterbalanced by antioxidant enzymes including SOD and catalase. It is well known that ROS, especially $\mathrm{O}_{2}{ }^{-}$, mediate several pathophysiological responses in the vessel wall. $\mathrm{O}_{2}^{-}$inactivates $\mathrm{NO}$, thus counteracting its vasodilator, antiproliferative, and anti-inflammatory effects $[1,55]$. Also, $\mathrm{O}_{2}^{-}$reacts extremely fast with $\mathrm{NO}$ to form the potent peroxynitrite anion $\mathrm{ONOO}^{-}$, which has injurious effects on vascular cells and leads to eNOS uncoupling. On the other hand, $\mathrm{H}_{2} \mathrm{O}_{2}$ derived from $\mathrm{O}_{2}{ }^{-}$is involved in vascular smooth muscle cell proliferation, apoptosis and migration [1].

An intensive research has been developed regarding the identification of antioxidant drugs able to attenuate vascular injuries related to oxidative stress [55-57]. Nevertheless, a proper identification of antioxidant substances requires reliable and direct approaches for monitoring the ROS responsible for the vascular damage. The existence of such a series of interconnected ROS pathways and their rapid degradation, explains why determining the exact dynamic and direct quantification of ROS has not yet been fully achieved.
Several spectroscopic and electrochemical methods are currently used for monitoring ROS production in living cells. These techniques are particularly efficient when applied to immune cells in which ROS are generated in very high levels, as an oxidative burst in response to the appropriate stimuli. In vascular cells and tissues, where ROS production occurs at lower levels, many of these approaches are limited by insufficient sensitivity and other practical considerations $[5,58]$. For instance, reduction of cytochrome $c$ has been widely used for measurement of $\mathrm{O}_{2}^{-}$production by isolated enzymes, cell homogenates and neutrophils [58]. However, cytochrome $c$ is cell impermeant and hence this assay only measures extracellular $\mathrm{O}_{2}^{-}$. In addition, reduced cytochrome $c$ can be reoxidized by oxidases, peroxidases and oxidants, thereby underestimating the rate of $\mathrm{O}_{2}^{-}[6,58]$. It has been suggested that the reproducibility of this method is very low, and not sensitive enough to detect the low levels of $\mathrm{O}_{2}{ }^{-}$found in vascular cells. Therefore, the cytochrome $c$ method is not widely used for detection of vascular $\mathrm{O}_{2}^{-}[6$, 58]. As stated by Bedioui and co-workers [12], the only strategies allowing direct, real time, label free and in vivo detection of ROS are those based on the use of selective microelectrodes. We will discuss below the most frequently used methods for ROS detection in vascular cells and tissues.

\subsection{Lucigenin-enhanced Chemiluminescence}

Chemiluminiscent methods for vascular detection of $\mathrm{O}_{2}{ }^{-}$ have been widely used due to the specificity of the probe with $\mathrm{O}_{2}^{-}$, low cellular toxicity and potential access to intracellular sites of $\mathrm{O}_{2}^{-}$production $[5,58]$. These methods consist on the use of a probe or enhancer that emits light during reaction with $\mathrm{O}_{2}^{-}$. Lucigenin is relatively specific for $\mathrm{O}_{2}{ }^{-}$and is the most frequently used enhancer for vascular detection of $\mathrm{O}_{2}^{-}$with a detection limit about $20 \mathrm{nM}$ [59]. Some investigations, however have suggested that lucigenin can undergo autoxidation and generate $\mathrm{O}_{2}^{-}$or even may reduce the acquired light signal, especially when high lucigenin concentrations (up to $250 \mu \mathrm{M}$ ) were used [5]. Therefore, the apparent rates of $\mathrm{O}_{2}^{-}$detected with this method might not reflect the real cellular ROS production. This limitation has been successfully minimized by using lower concentrations of lucigenin $(5 \mu \mathrm{M})$ [58]. In addition to this consideration, some practical precautions must be taken into account when using this assay e.g. the use of NOS inhibitors and a variety of ROS scavengers in vascular samples. Consequently, this method, although indirect, is reproducible, inexpensive and reliable for vascular $\mathrm{O}_{2}{ }^{-}$ determination. As illustrated in Fig. (3), lucigenin-enhanced chemiluminescence provides $\mathrm{O}_{2}^{-}$levels in arteries from animal models of hypertension, which is a well known status of vascular oxidative stress. Indeed, lucigenin-enhanced chemiluminescence represents a helpful approach for preliminary evaluation of the potential antioxidant properties of a molecule under investigation $[60,61]$.

\subsection{Fluorescent Probes for ROS}

In the last years, numerous studies have used fluorescent probes to detect ROS in cultured vascular cells and tissue sections. In these investigations, confocal microscopy has been frequently used to directly image the fluorescence 


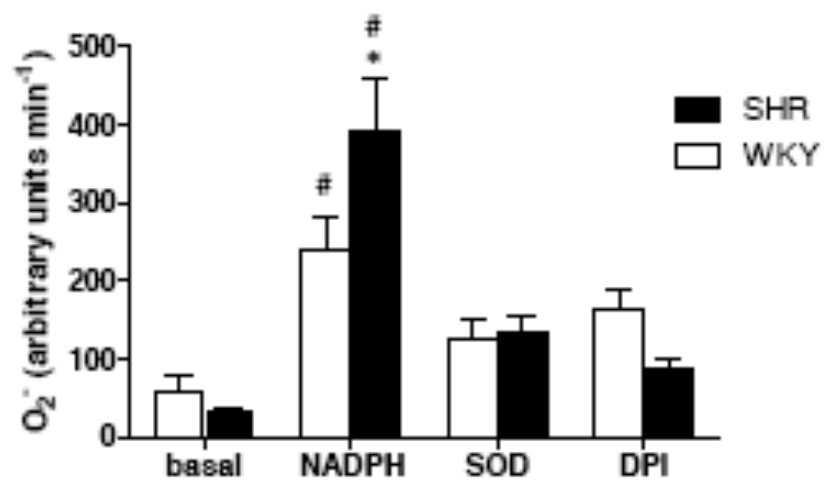

Fig. (3). Detection of $\mathrm{O}_{2}^{-}$by lucigenin-enhanced chemiluminescence in aortic segments isolated from Spontaneously Hypertensive Rats (SHR) and their normotensive strain Wistar Kyoto (WKY) rats. The detection was developed under basal and NADPH $\left(10^{-4} \mathrm{M}\right)$-stimulated conditions in the presence or absence of superoxide dismutase (SOD, $100 \mathrm{U} / \mathrm{ml}$ ) or the NADPH oxidase inhibitor diphenyleneiodonium chloride (DPI, $\left.10^{-5} \mathrm{M}\right)$. Data are means \pm SEM of $n=4$. ${ }^{*} \mathrm{P}<0.05$ vs $\mathrm{WKY}, \# \mathrm{P}<0.05$ vs strainmatched basal conditions.

produced by these dyes. Although these fluorescence-based assays are semi-quantitative they can provide relevant information about the localization of ROS in the vessel wall [58]. The most popular fluorescent dye to measure vascular $\mathrm{O}_{2}{ }^{-}$is dihydroethidium (DHE) or hydroethidine. DHE is cell permeable and interacts with intracellular $\mathrm{O}_{2}^{-}$to form 2hydroxyethidium, which in turn intercalates with DNA providing fluorescence at an excitation wavelength of 520 $\mathrm{nm}$ and an emission wavelength of $610 \mathrm{~nm}$ [6]. This form is relatively specific for $\mathrm{O}_{2}{ }^{-}$with minimal potential of being oxidized by $\mathrm{H}_{2} \mathrm{O}_{2}$. Accordingly, using $520 / 610 \mathrm{~nm}$ should avoid eventual non-specific overlapping fluorescence induced by $\mathrm{H}_{2} \mathrm{O}_{2}$. It is also recommended to use cell permeable SOD mimetics (e.g. polyethylene glycolconjugated SOD) in parallel to minimize this non-specific reaction $[6,62]$. DHE staining is a very sensitive and generally reproducible procedure, convenient to use as an initial screening for vascular $\mathrm{O}_{2}^{-}$production in cells and tissues. For instance, production of $\mathrm{O}_{2}^{-}$induced by endothelin-1 has been determined in sections from rat aorta and small mesenteric arteries by using DHE assays (Fig. (4)). This approach may hence provide important preliminary data about the antioxidant activity of natural molecules such as dietary flavonoids in rat arteries [61]. The results derived from DHE-based method should be confirmed by direct approaches such as ESR or selective microelectrodes.

The evaluation of DHE fluorescence is limited by the possible simultaneous detection of its two main products: 2hydroxyethidium, which results from the specific interaction of DHE with $\mathrm{O}_{2}^{-}$, and ethidium, mainly associated with pathways involving $\mathrm{H}_{2} \mathrm{O}_{2}$ and metal-based oxidizing systems (e.g. heme proteins and peroxidases). Both DHE-derived compounds are fluorescent products difficult to discriminate between each other by conventional fluorescent microscopy or fluorometry. Thus, high-performance liquid chromatography (HPLC) analysis of DHE-derived fluorescent compounds has been developed $[63,64]$ and validated in the



Fig. (4). Dihydroethidium staining for $\mathrm{O}_{2}{ }^{-}$detection in rat aortic and small mesenteric artery (SMA) sections in control conditions or incubated with endothelin-1 (ET-1) (1 $\mathrm{mg} / \mathrm{ml})$. The red fluorescence indicates an intense $\mathrm{O}_{2}{ }^{-}$production in all layers of the arterial wall.

vascular system [65] in order to achieve separation and individual analysis of such products. This technique provides a significant increase in the accuracy of $\mathrm{O}_{2}{ }^{-}$output determinations and is an important advance toward the precise quantification of $\mathrm{O}_{2}^{-}$in cells and tissues.

A cationic derivative of DHE, named MitoSOX Red indicator, has been recently designed for highly selective detection of $\mathrm{O}_{2}^{-}$in the mitochondria of living cells. Oxidation of MitoSOX Red probe by $\mathrm{O}_{2}^{-}$results in a 2hydroxyethidium derivative that exhibits a fluorescence excitation peak at $400 \mathrm{~nm}$ absent in the excitation spectrum of products derived from ethidium oxidation by ROS other than $\mathrm{O}_{2}^{-}$[66]. Therefore, fluorescence excitation at $400 \mathrm{~nm}$ with emission detection at $590 \mathrm{~nm}$ provides optimum discrimination of $\mathrm{O}_{2}{ }^{-}$from other ROS. The MitoSOX Red indicator has been used for confocal microscopy analysis of ROS generation by mitochondrial NO synthase in cat ventricular myocytes [67]. MitoSOX Red has also been applied in combination with Ample Red reagent, which is a specific fluorescent indicator of $\mathrm{H}_{2} \mathrm{O}_{2}$, for measurement of mitochondrial $\mathrm{O}_{2}^{-}$and $\mathrm{H}_{2} \mathrm{O}_{2}$ production in rat vascular endothelial cells [68]. Mukhopadhyay and co-workers [69] established a method for simultaneous measurements of mitochondrial $\mathrm{O}_{2}{ }^{-}$production using MitoSOX Red probe in combination with apoptotic markers by both flow cytometry and confocal microscopy in human coronary artery endothelial cell lines. The authors propose that the application of this methodology combined with fluorescent microscopy may be very useful to reveal important spatial-temporal changes in mitochondrial $\mathrm{O}_{2}^{-}$production and execution of programmed cell death in virtually any cell type. Despite the potential advantages of this probe, some authors consider that the chemical reactivity of MitoSOX with $\mathrm{O}_{2}{ }^{-}$is similar to the reactivity of DHE with $\mathrm{O}_{2}{ }^{-}$, and therefore, all of the 
limitations attributed to the DHE assay are applicable to MitoSOX as well [70].

The fluorescent dye 2',7'-dichlorodihydrofluorescein (DCFH) has been also used to detect ROS in cultured cells. The use of this probe in vascular cells or tissues is not further extended as DHE, maybe due to the fact that DCFH is not very specific and yields fluorescence in response to several ROS including $\mathrm{H}_{2} \mathrm{O}_{2}$, $\mathrm{ONOO}^{-}$and $\mathrm{OH}^{\circ}$. DCFH may also autoxidize to form $\mathrm{H}_{2} \mathrm{O}_{2}$. Despite the use of DCFH can be problematic, it may be an approach for vascular ROS detection, except for $\mathrm{O}_{2}{ }^{-}$determination. In this regard, Chin and co-workers have recently determined intracellular levels of $\mathrm{H}_{2} \mathrm{O}_{2}$ and $\mathrm{OH}^{-}$by using the fluorescent probe DCFH diacetate $\left(\mathrm{H}_{2}\right.$ DCFDA) within human vascular endothelial cells from umbilical vein cultured in a hemodynamic Labon-a-chip system [71]. The authors evaluated the levels of ROS in endothelial cells in response to various shear stresses either alone or in combination with different glucose concentrations to mimic hyperglycemic conditions. Although the detection of ROS is similar to previous approaches regarding sensitivity and specificity, the advantage of this Lab-on-a-chip system over conventional setups is that it provides the use of pulsatile shear stress to represent the physiological conditions of the blood flow.

\subsection{ESR Spectroscopy}

Both electrochemical and ESR-based methods are currently the only analytical approaches allowing a direct detection of ROS. The ESR technique is based on the magnetic properties of the unpaired electrons in ROS, as previously described (see section 2.2 ). It is very common the use of spin traps, which reacts with ROS incorporating the radical into their structure $[5,28,58]$. The most frequently used spin traps for ROS detection are the pyrroline-based cyclic nitrones, such as DMPO and DEPMPO, which react with the $\mathrm{OH}^{-}$and $\mathrm{O}_{2}^{-}$radicals to form $-\mathrm{OH}$ and $-\mathrm{OOH}$ adducts, respectively. A limitation of this assay is that the product of the trap-ROS interaction can be either metabolized or reduced by endogenous antioxidants [72]. However, later studies provided evidence that cyclic hydroxylamines can react with $\mathrm{O}_{2}^{-}$to form more stable adducts compared to those with nitrone spin traps [6]. There are several investigations using these spin traps to selectively and effectively measure $\mathrm{O}_{2}^{-}$production in vascular cultured cells or tissue homogenates [73, 74].

Although ESR spin trapping is an useful strategy for ROS determination in vivo/in vitro with a detection limit of $1 \mathrm{nM}$ for $\mathrm{O}_{2}{ }^{-}$, it requires spin traps that reduce specificity and stability to the measure. In addition to the main limitations already described in section 2.2, the ESR set up is a cumbersome and expensive system that makes difficult the application in vivo, particularly in humans [11].

\subsection{Electrochemical Detection}

The use of electrochemical methods for ROS detection must solve important limitations already described with previous approaches, including: 1) the difficulty of the assays to discriminate between $\mathrm{O}_{2}{ }^{-}$and other ROS; 2) the inability to be applied in vivo. Then, microelectrode-based strategies allow direct, real time, label free and in vivo detection of ROS. Development of new ROS microsensors is currently in progress to specifically measure vascular $\mathrm{O}_{2}$ and other ROS in vivo/in vitro and even for simultaneous determinations of vascular production of ROS and RNS [11, 12, 75]. Recently, Bedioui and co-workers [12] have extensively reviewed the most significant strategies for electrochemical detection of ROS and RNS in biological systems, with especial attention paid to $\mathrm{O}_{2}^{-}$and NO. A detection limit between $5 \mu \mathrm{M}$ and $15 \mathrm{nM}$ has been achieved for $\mathrm{O}_{2}^{-}$in living cells $[12,59]$. While several microelectrodes have been recently designed for detection of $\mathrm{O}_{2}{ }^{-}$and of other ROS in living cells such as neutrophils and macrophages $[12,76,77]$, the application of these sensors to vascular cells or tissues requires further testing and evaluation. Accordingly, Fujita and co-workers recently developed a novel $\mathrm{O}_{2}^{-}$electrochemical sensor to monitor and evaluate in vivo $\mathrm{O}_{2}^{-}$generation in circulating blood of rats [75]. Nevertheless, it has been suggested that the adoption of smaller diameter sensors could improve the in vivo application in humans or animals as a low invasive method for monitoring oxidative stress in blood vessels [11].

\section{CONCLUSION}

Vascular generation of ROS and NO plays a crucial role in the function of blood vessel and their production is tightly regulated to maintain vascular homeostasis. An intensive research has been focused on the identification of drugs and natural antioxidants able to rebalance vascular ROS and RNS levels, altered by cardiovascular diseases. An increasing attention has been paid in revealing their mechanisms of action by measuring spatial and temporal distribution and levels of ROS and RNS in living cells. Therefore, a better understanding of ROS and RNS in vascular function will improve targeting specific sources, locations, cell types or even treatment of cardiovascular diseases. In addition, development of novel and more effective approaches directed to selective and sensitive measuring of vascular ROS and RNS may assess the beneficial antioxidant properties of drugs.

The present review describes the main methods that have been applied to determine vascular NO and ROS. Only NO microsensors, ESR, and NO sensitive fluorescent probes allow real time estimation of $\mathrm{NO}$ concentrations in cell suspensions, cell cultures, and isolated vascular segments in vitro. Of these techniques only NO microsensors have so far been developed for real time detection of NO in vivo. ROS formation has been detected in cell cultures by lucigeninenhanced fluorescence, fluorescent probes e.g. DCFH and DHE, by use of ESR, and also by electrochemical detection. Strategies based on the use of microelectrodes are hence the only that allow direct, real time, label free and in vivo detection of NO and ROS. The use of electrochemical methods for ROS and RNS detection may solve important limitations that entail the use of other approaches already described, including specificity and application in vivo. The limitations of the electrochemical microsensors currently used for measuring ROS and RNS include interference from other substances, physical force on the sensors, and influence of temperature and changes in $\mathrm{pH}$ that may lead to artifactual changes in current. Regarding that, specificity 
testing and calibration are pivotal, and in case of ROS, application of more than one technique is recommendable.

Technical advances have allowed simultaneous detection of both NO and ROS by use of electrochemical microsensors. Miniaturizing the sensors may allow incorporation of those in lab-on-a-chip systems and may also lead to real time measurements of $\mathrm{NO}$ and ROS in the coronary circulation in situ, thus providing direct evaluation of endothelial and vascular function in cardiovascular disease. Additionally, an intensive research is now focused in developing electrochemical/optical sensors devoted to the simultaneous sensitive and selective detection of specific ROS or RNS in vascular cells and tissues. The application of these novel and combined approaches in complex situations such as in vivo or for clinical tests remains a future challenge. Such tools and real-time measurement strategies may open the door to identify very fast and intricate biochemical processes regulating $\mathrm{NO}$ and ROS release under different pathophysiological conditions. After further improvements, these promising approaches may open new diagnostic and therapeutic possibilities in patients with cardiovascular diseases and related complications.

\section{ACKNOWLEDGEMENT}

Declared none.

\section{CONFLICT OF INTEREST}

Declared none.

\section{REFERENCES}

[1] Papaharalambus, C.A.; Griendling, K.K. Basic mechanisms of oxidative stress and reactive oxygen species in cardiovascular injury. Trends Cardiovasc. Med., 2007, 17(2), 48-54.

[2] Förstermann, U. Oxidative stress in vascular disease: causes, defense mechanisms and potential therapies. Nat. Clin. Pract. Cardiovasc. Med., 2008, 5(6), 338-349.

[3] Simonsen, U.; Rodriguez-Rodriguez, R.; Dalsgaard, T.; Buus, N.H.; Stankevicius, E. Novel approaches to improving endothelium-dependent nitric oxide-mediated vasodilatation. Pharmacol. Rep., 2009, 61(1), 105-115.

[4] Vásquez-Vivar, J.; Martásek, P.; Whitsett, J.; Joseph, J.; Kalyanaraman, B. The ratio between tetrahydrobiopterin and oxidized tetrahydrobiopterin analogues controls superoxide release from endothelial nitric oxide synthase: an EPR spin trapping study. Biochem. J., 2002, 362, 733-739.

[5] Tarpey, M.M.; Fridovich, I. Methods of detection of vascular reactive species: nitric oxide, superoxide, hydrogen peroxide, and peroxynitrite. Circ. Res., 2001, 89(3), 224-236.

[6] Cai, H.; Dikalov, S.; Griendling, K.K.; Harrison, D.G. Detection of reactive oxygen species and nitric oxide in vascular cells and tissues: comparison of sensitivity and specificity. Methods Mol. Med., 2007, 139, 293-311.

[7] Wadsworth, R.; Stankevicius, E.; Simonsen, U. Physiologically relevant measurements of nitric oxide in cardiovascular research using electrochemical microsensors. J. Vasc. Res., 2006, 43(1), 7085.

[8] Hall, C.N.; Garthwaite, J. What is the real physiological NO concentration in vivo? Nitric Oxide, 2009, 21(2), 92-103.

[9] Takarada, S.; Imanishi, T.; Goto, M.; Mochizuki, S.; Ikejima, H.; Tsujioka, H.; Kuroi, A.; Takeshita, T.; Akasaka, T. First evaluation of real-time nitric oxide changes in the coronary circulation in patients with non-ischaemic dilated cardiomyopathy using a catheter-type sensor. Eur. Heart J., 2010, 31(23), 2862-2870.

[10] Lindon, H.Y.; Qian, C.; Weis, M.T. Direct Measurement of Hydrogen Peroxide (H2O2) or Nitric Oxide (NO) Release: A
Powerful Tool to Assess Real-time Free Radical Production in Biological Models. Am. J. Biomed. Sci., 2011, 3(1), 40-48.

[11] Malinski, T.; Mesaros, S.; Tomboulian, P. Nitric oxide measurement using electrochemical methods. Methods Enzymol., 1996, 268, 58-69.

[12] Bedioui, F.; Quinton, D.; Griveau, S.; Nyokong, T. Designing molecular materials and strategies for the electrochemical detection of nitric oxide, superoxide and peroxynitrite in biological systems. Phys. Chem. Chem. Phys., 2010, 12(34), 9976-9988.

[13] Kalinowski, L.; Matys, T.; Chabielska, E.; Buczko, W.; Malinski, T. Angiotensin II AT1 receptor antagonists inhibit platelet adhesion and aggregation by nitric oxide release. Hypertension, 2002, 40(4), 521-527.

[14] Heitsch, H.; Brovkovych, S.; Malinski, T.; Wiemer, G. Angiotensin-(1-7)-Stimulated Nitric Oxide and Superoxide Release From Endothelial Cells. Hypertension, 2001, 37(1), 72-76.

[15] Kalinowski, L.; Dobrucki, L.W.; Brovkovych, V.; Malinski, T. Increased nitric oxide bioavailability in endothelial cells contributes to the pleiotropic effect of cerivastatin. Circulation, 2002, 105(8), 933-938.

[16] Brovkovych, V.; Stolarczyk, E.; Oman, J.; Tomboulian, P.; Malinski, T. Direct electrochemical measurement of nitric oxide in vascular endothelium. J. Pharm. Biomed. Anal., 1999, 19(1-2), 135-143.

[17] Kanai, A.J.; Mesaros, S.; Finkel, M.S.; Oddis, C.V.; Birder, L.A.; Malinski, T. Beta-adrenergic regulation of constitutive nitric oxide synthase in cardiac myocytes. Am. J. Physiol., 1997, 273(4 Pt 1), C1371-C1377.

[18] Tschudi, M.R.; Mesaros, S.; Lüscher, T.F.; Malinski, T. Direct in situ measurement of nitric oxide in mesenteric resistance arteries. Increased decomposition by superoxide in hypertension. Hypertension, 1996, 27(1), 32-35.

[19] Oemar, B.S.; Tschudi, M.R.; Godoy, N.; Brovkovich, V.; Malinski, T.; Lüscher, T.F. Reduced endothelial nitric oxide synthase expression and production in human atherosclerosis. Circulation, 1998, 97(25), 2494-2498.

[20] Simonsen, U.; Wadsworth, R.M.; Buus, N.H.; Mulvany, M.J. In vitro simultaneous measurements of relaxation and nitric oxide concentration in rat superior mesenteric artery. J. Physiol., 1999, 516( Pt 1), 271-282.

[21] Hernanz, R.; Alonso, M.J.; Zibrandtsen, H.; Alvarez, Y.; Salaices, M.; Simonsen, U. Measurements of nitric oxide concentration and hyporeactivity in rat superior mesenteric artery exposed to endotoxin. Cardiovasc. Res., 2004, 62(1), 202-211.

[22] Rodriguez-Rodriguez, R.; Stankevicius, E.; Herrera, M.D.; Ostergaard, L.; Andersen, M.R.; Ruiz-Gutierrez, V.; Simonsen, U. Oleanolic acid induces relaxation and calcium-independent release of endothelium-derived nitric oxide. Br. J. Pharmacol., 2008, 155(4), 535-546.

[23] Hedegaard, E.R.; Stankevicius, E.; Simonsen, U.; Fröbert, O. Nonendothelial endothelin counteracts hypoxic vasodilation in porcine large coronary arteries. BMC Physiol., 2011, 11(1), 8.

[24] Pasgaard; T.; Stankevicius, E.; Jørgensen, M.M.; Ostergaard, L.; Simonsen, U.; Frøbert, O. Hyperoxia reduces basal release of nitric oxide and contracts porcine coronary arteries. Acta Physiol. (Oxf)., 2007, 191(4), 285-296.

[25] Bohlen, H.G.; Nase, G.P. Dependence of intestinal arteriolar regulation on flow-mediated nitric oxide formation. Am. J. Physiol. Heart Circ. Physiol., 2000, 279(5), H2249-2258.

[26] Huk, I; Nanobashvili, J.; Neumayer, C.; Punz, A.; Mueller, M.; Afkhampour, K.; Mittlboeck, M.; Losert, U.; Polterauer, P.; Roth, E.; Patton, S.; Malinski, T. L-arginine treatment alters the kinetics of nitric oxide and superoxide release and reduces ischemia/reperfusion injury in skeletal muscle. Circulation, 1997, 96(2), 667-675.

[27] Kutzsche, S.; Kirkeby, O.J.; Rise, I.R.; Saugstad, O.D. Effects of hypoxia and reoxygenation with $21 \%$ and $100 \%$-oxygen on cerebral nitric oxide concentration and microcirculation in newborn piglets. Biol. Neonate., 1999, 76(3), 153-167.

[28] Villamena, F.A.; Zweier, J.L. Detection of reactive oxygen and nitrogen species by EPR spin trapping. Antioxid. Redox Signal., 2004, 6(3), 619-629.

[29] Lecour, S.; Chevet, D.; Maupoil, V.; Moisant, M.; Bernard, C.; Zahnd, J.P.; Touchard, G.; Briot, F.; Rochette, L. Intrarenal detection of nitric oxide using electron spin resonance spectroscopy 
in hypertensive lipopolysaccharide-treated rats. J. Cardiovasc. Pharmacol., 2002, 40(1), 9-17.

[30] Alzawahra, W.F.; Talukder, M.A.; Liu, X.; Samouilov, A.; Zweier, J.L. Heme proteins mediate the conversion of nitrite to nitric oxide in the vascular wall. Am. J. Physiol. Heart Circ. Physiol., 2008, 295(2), H499-508.

[31] Loibl, S.; von Minckwitz, G.; Weber, S.; Sinn, H.P.; Schini-Kerth, V.B.; Lobysheva, I.; Nepveu, F.; Wolf, G.; Strebhardt, K.; Kaufmann, M. Expression of endothelial and inducible nitric oxide synthase in benign and malignant lesions of the breast and measurement of nitric oxide using electron paramagnetic resonance spectroscopy. Cancer, 2002, 95(6), 1191-1198.

[32] Vanin, A.; Poltorakov, A. NO spin trapping in biological systems. Front. Biosci., 2009, 14, 4427-4435.

[33] Khoo, J.P.; Alp, N.J.; Bendall, J.K.; Kawashima, S.; Yokoyama, M.; Zhang, Y.H.; Casadei, B.; Channon, K.M. EPR quantification of vascular nitric oxide production in genetically modified mouse models. Nitric Oxide, 2004, 10(3), 156-161.

[34] Kleschyov, A.L.; Münzel, T. Advanced spin trapping of vascular nitric oxide using colloid iron diethyldithiocarbamate. Methods Enzymol., 2002, 359, 42-51.

[35] Gomes, A.; Fernandes, E.; Lima, J.L. Use of fluorescence probes for detection of reactive nitrogen species: a review. J. Fluoresc., 2006, 16(1), 119-139.

[36] Kojima, H.; Nakatsubo, N.; Kikuchi, K.; Kawahara, S.; Kirino, Y.; Nagoshi, H.; Hirata, Y.; Nagano, T. Detection and imaging of nitric oxide with novel fluorescent indicators: diaminofluoresceins. Anal. Chem., 1998, 70(13), 2446-2453.

[37] Qiu, W.; Kass, D.A.; Hu, Q.; Ziegelstein, R.C. Determinants of shear stress-stimulated endothelial nitric oxide production assessed in real-time by 4,5-diaminofluorescein fluorescence. Biochem. Biophys. Res. Commun., 2001, 286, 328-335.

[38] Montagnani, M.; Chen, H.; Barr, V.A.; Quon, M.J. Insulinstimulated activation of eNOS is independent of $\mathrm{Ca} 2+$ but requires phosphorylation by Akt at Ser(1179). J. Biol. Chem., 2001, 276, 30392-30398.

[39] Chen, H.; Montagnani, M.; Funahashi, T.; Shimomura, I.; Quon, M.J. Adiponectin stimulates production of nitric oxide in vascular endothelial cells. J. Biol. Chem., 2003, 278, 45021-45026.

[40] Strijdom, H.; Jacobs, S.; Hattingh, S.; Page, C.; Lochner, A. Nitric oxide production is higher in rat cardiac microvessel endothelial cells than ventricular cardiomyocytes in baseline and hypoxic conditions: a comparative study. FASEB J., 2006, 20, 314-316.

[41] Zhou, X.; He, P. Improved measurements of intracellular nitric oxide in intact microvessels using 4,5-diaminofluorescein diacetate. Am. J. Physiol. Heart Circ. Physiol., 2011, 301(1), H108-114.

[42] Yi, F.X.; Zhang, A.Y.; Campbell, W.B.; Zou, A.P.; Van Breemen, C.; Li, P.L. Simultaneous in situ monitoring of intracellular Ca2+ and NO in endothelium of coronary arteries. Am. J. Physiol. Heart Circ. Physiol., 2002, 283, H2725-2732.

[43] Zhu, L.; He, P. Platelet-activating factor increases endothelial $[\mathrm{Ca} 2+] \mathrm{i}$ and $\mathrm{NO}$ production in individually perfused intact microvessels. Am. J. Physiol. Heart Circ. Physiol., 2005, 288, H2869-2877.

[44] Ye, X.; Rubakhin, S.S.; Sweedler, J.V. Detection of nitric oxide in single cells. Analyst., 2008, 133(4), 423-433.

[45] McQuade, L.E.; Lippard, S.J. Fluorescent probes to investigate nitric oxide and other reactive nitrogen species in biology (truncated form: fluorescent probes of reactive nitrogen species). Curr. Opin. Chem. Biol., 2010, 14(1), 43-49.

[46] Balcerczyk, A.; Soszynski, M.; Bartosz, G. On the specificity of 4amino-5-methylamino-2',7'-difluorofluorescein as a probe for nitric oxide. Free Radic. Biol. Med., 2005, 39(3), 327-335.

[47] Kojima, H.; Nakatsubo, N.; Kikuchi, K.; Urano, Y.; Higuchi, T.; Tanaka, J.; Kudo, Y.; Nagano, T. Direct evidence of NO production in rat hippocampus and cortex using a new fluorescent indicator: DAF-2 DA. Neuroreport., 1998, 9(15), 3345-3348.

[48] Kojima, H.; Hirotani, M.; Nakatsubo, N.; Kikuchi, K.; Urano, Y.; Higuchi, T.; Hirata, Y.; Nagano, T. Bioimaging of nitric oxide with fluorescent indicators based on the rhodamine chromophore. Anal. Chem., 2001, 73(9), 1967-1973.

[49] Lacza, Z.; Horváth, E.M.; Pankotai, E.; Csordás, A.; Kollai, M.; Szabó, C.; Busija, D.W. The novel red-fluorescent probe DAR-4M measures reactive nitrogen species rather than NO. J. Pharmacol. Toxicol. Methods., 2005, 52(3), 335-340.
[50] Wardman, P. Fluorescent and luminescent probes for measurement of oxidative and nitrosative species in cells and tissues: progress, pitfalls, and prospects. Free Radic. Biol. Med., 2007, 43(7), 9951022.

[51] Huang, K.J.; Wang, H.; Ma, M.; Zhang, X.; Zhang, H.S. Real-time imaging of nitric oxide production in living cells with $1,3,5,7-$ tetramethyl-2,6-dicarbethoxy-8-(3',4'-diaminophenyl)-

difluoroboradiaza-s-indacence by invert fluorescence microscope. Nitric Oxide., 2007, 16(1), 36-43.

[52] Ouyang, J.; Hong, H.; Shen, C.; Zhao, Y.; Ouyang, C.; Dong, L.; Zhu, J.; Guo, Z.; Zeng, K.; Chen, J.; Zhang, C.; Zhang, J. A novel fluorescent probe for the detection of nitric oxide in vitro and in vivo. Free Radic. Biol. Med., 2008, 45(10), 1426-1436.

[53] Sato, M.; Hida, N.; Umezawa, Y. Imaging the nanomolar range of nitric oxide with an amplifier-coupled fluorescent indicator in living cells. Proc. Natl. Acad. Sci. U.S.A., 2005, 102(41), 1451514520 .

[54] Sato M, Nakajima T, Goto M, Umezawa Y. Cell-based indicator to visualize picomolar dynamics of nitric oxide release from living cells. Anal. Chem., 2006, 78(24), 8175-8182.

[55] Thomas, S.R.; Witting, P.K.; Drummond, G.R. Redox control of endothelial function and dysfunction: molecular mechanisms and therapeutic opportunities. Antioxid. Redox Signal., 2008, 10(10), $1713-1765$

[56] Hamilton, C.A.; Miller, W.H.; Al-Benna, S.; Brosnan, M.J.; Drummond, R.D.; McBride, M.W.; Dominiczak, A.F. Strategies to reduce oxidative stress in cardiovascular disease. Clin. Sci. (Lond), 2004, 106(3), 219-234

[57] Drummond, G.R.; Selemidis, S.; Griendling, K.K.; Sobey, C.G Combating oxidative stress in vascular disease: NADPH oxidases as therapeutic targets. Nat. Rev. Drug Discov., 2011, 10(6), 453471.

[58] Münzel, T.; Afanas'ev, I.B.; Kleschyov, A.L.; Harrison, D.G. Detection of superoxide in vascular tissue. Arterioscler. Thromb. Vasc. Biol., 2002, 22(11), 1761-1768.

[59] Mesáros, S.; Vanková, Z.; Mesárošová, A.; Tomčík, P.; Grunfeld, $\mathrm{S}$. Electrochemical determination of superoxide and nitric oxide generated from biological samples. Bioelectrochemistry and Bioenergetics, 1998, 46(1), 33-37.

[60] de Sotomayor, M.A.; Mingorance, C.; Rodriguez-Rodriguez, R.; Marhuenda, E.; Herrera, M.D. L-carnitine and its propionate: improvement of endothelial function in SHR through superoxide dismutase-dependent mechanisms. Free Radic. Res., 2007, 41(8), 884-891.

[61] Romero, M.; Jiménez, R.; Sánchez, M.; López-Sepúlveda, R.; Zarzuelo, M.J.; O'Valle, F.; Zarzuelo, A.; Pérez-Vizcaíno, F.; Duarte, J. Quercetin inhibits vascular superoxide production induced by endothelin-1: Role of NADPH oxidase, uncoupled eNOS and PKC. Atherosclerosis, 2009, 202(1), 58-67.

[62] Patsoukis, N.; Papapostolou, I.; Georgiou, C.D. Interference of non-specific peroxidases in the fluorescence detection of superoxide radical by hydroethidine oxidation: a new assay for H2O2. Anal. Bioanal. Chem., 2005, 381(5), 1065-1072.

[63] Fink, B.; Laude, K.; McCann, L.; Doughan, A.; Harrison, D.G.; Dikalov, S. Detection of intracellular superoxide formation in endothelial cells and intact tissues using dihydroethidium and an HPLC-based assay. Am. J. Physiol. Cell. Physiol., 2004, 287(4), C895-902.

[64] Zhao, H.; Joseph, J.; Fales, H.M.; Sokoloski, E.A.; Levine, R.L.; Vasquez-Vivar, J.; Kalyanaraman, B. Detection and characterization of the product of hydroethidine and intracellular superoxide by HPLC and limitations of fluorescence. Proc. Natl. Acad. Sci. U S A., 2005, 102(16), 5727-5732.

[65] Fernandes, D.C.; Wosniak, J. Jr.; Pescatore, L.A.; Bertoline, M.A. Liberman, M.; Laurindo, F.R.; Santos, C.X. Analysis of DHEderived oxidation products by HPLC in the assessment of superoxide production and NADPH oxidase activity in vascular systems. Am. J. Physiol. Cell. Physiol., 2007, 292(1), C413-422.

[66] Robinson, K.M.; Janes, M.S.; Beckman, J.S. The selective detection of mitochondrial superoxide by live cell imaging. Nat. Protoc., 2008, 3, 941-947.

[67] Dedkova, E.N.; Blatter, L.A. Characteristics and function of cardiac mitochondrial nitric oxide synthase. J. Physiol., 2009, 587, 851-872

[68] Ungvari, Z.; Labinskyy, N.; Gupte, S.; Chander, P.N.; Edwards, J.G.; Csiszar, A. Dysregulation of mitochondrial biogenesis in 
vascular endothelial and smooth muscle cells of aged rats. Am. J. Physiol. Heart Circ. Physiol., 2008, 294, H2121-H2128.

[69] Mukhopadhyay, P.; Rajesh, M.; Haskó, G.; Hawkins, B.J.; Madesh, M.; Pacher, P. Simultaneous detection of apoptosis and mitochondrial superoxide production in live cells by flow cytometry and confocal microscopy. Nat. Protoc., 2007, 2(9), 2295-2301.

[70] Zielonka, J.; Kalyanaraman, B. Hydroethidine- and MitoSOXderived red fluorescence is not a reliable indicator of intracellular superoxide formation: another inconvenient truth. Free Radic. Biol. Med., 2010, 48(8), 983-1001.

[71] Chin, L.K.; Yu, J.Q.; Fu, Y.; Yu, T.; Liu, A.Q.; Luo, K.Q. Production of reactive oxygen species in endothelial cells under different pulsatile shear stresses and glucose concentrations. Lab Chip., 2011, 11(11), 1856-1863.

[72] Halliwell, B.; Whiteman, M. Measuring reactive species and oxidative damage in vivo and in cell culture: how should you do it and what do the results mean? Br. J. Pharmacol., 2004, 142(2), 231-55.

[73] Landmesser, U.; Cai, H.; Dikalov, S.; McCann, L.; Hwang, J.; Jo, H.; Holland, S.M.; Harrison, D.G. Role of p47(phox) in vascular oxidative stress and hypertension caused by angiotensin II. Hypertension, 2002, 40(4), 511-515.

[74] Spiekermann, S.; Landmesser, U.; Dikalov, S.; Bredt, M.; Gamez, G.; Tatge, H.; Reepschläger, N.; Hornig, B.; Drexler, H.; Harrison, D.G. Electron spin resonance characterization of vascular xanthine and $\mathrm{NAD}(\mathrm{P}) \mathrm{H}$ oxidase activity in patients with coronary artery disease: relation to endothelium-dependent vasodilation. Circulation., 2003, 107(10), 1383-1389.

[75] Fujita, M.; Tsuruta, R.; Kasaoka, S.; Fujimoto, K.; Tanaka, R.; Oda, Y.; Nanba, M.; Igarashi, M.; Yuasa, M.; Yoshikawa, T.; Maekawa, T. In vivo real-time measurement of superoxide anion radical with a novel electrochemical sensor. Free Radic. Biol. Med., 2009, 47(7), 1039-1048.

[76] Li, H.; Li, Q.; Wang, X.; Xu, K.; Chen, Z.; Gong, X.; Liu, X.; Tong, L.; Tang, B. Simultaneous determination of superoxide and hydrogen peroxide in macrophage RAW 264.7 cell extracts by microchip electrophoresis with laser-induced fluorescence detection. Anal. Chem., 2009, 81(6), 2193-2198.

[77] Shleev, S.; Wetterö, J.; Magnusson, K.E.; Ruzgas, T. Simultaneous use of electrochemistry and chemiluminescence to detect reactive oxygen species produced by human neutrophils. Cell. Biol. Int., 2008, 32(12), 1486-1496. 